\title{
BACILLUS THURINGIENSIS: DIVERSIDADE GÊNICA EM ISOLADOS LEPIDOPTERA-ESPECÍFICOS
}

\author{
A.M. Guidelli-Thuler ${ }^{1}$, J.A.D. Sena ${ }^{1}$, I.L. Abreu ${ }^{1}$, C.C. Davolos ${ }^{1}$, \\ S.B. Alves ${ }^{2}$, R.A. Polanczyk ${ }^{3}$, F.H. Valicente ${ }^{4}$, M.V.F. Lemos ${ }^{1}$
}

${ }^{1}$ Universidade Estadual Paulista, Faculdade de Ciências Agrárias e Veterinarias, Departamento de Biologia Aplicada à Agropecuária, Via de Acesso Prof. Paulo Donato Castellane, s/no, CEP 14884-900, Jaboticabal, SP, Brasil. E-mail: guidelli@fcav.unesp.br

\section{RESUMO}

\begin{abstract}
O presente trabalho teve como objetivo caracterizar geneticamente 1.073 isolados de Bacillus thuringiensis, de três coleções brasileiras, provenientes da UNESP, Jaboticabal, da ESALQ/ Piracicaba e da EMBRAPA. Sete Lagoas, analisando os tipos de genes cry 1 apresentados pelos isolados. Para isso, foram elaborados oligonucleotídeos iniciadores a partir de 16 regiões conservadas e 4 regiões não conservadas das seqüências de cada uma das 16 subclasses do gene cry1. Essas seqüências foram amplificadas por PCR e a presença de amplicons para cada subclasse foi calculada em porcentagem por gene e por coleção. Nessa análise, 55,7\% dos isolados apresentaram amplificação para o gene cry 1 , e as subclassescry $1 A a, c r y 1 A b, c r y 1 A c, c r y 1 A d, c r y 1 A e$, cry1Af, cry1Ag, e cry1Bf, cry1Ca e cry1Fa estão presentes em alta proporção de isolados, variando de $43,4 \%$ a $54,9 \%$. Verificou-se que existe uma distribuição das subclasses dentro do banco de isolados de $B$. thuringiensis em estudo, com maior porcentagem de isolados portadores dos genes cry $1 A b(42,12 \%)$ e com menor porcentagem de representantes da subclasse $c r y 1 D b(0,6 \%)$. A variabilidade gênica, nas coleções analisadas, destaca as coleções de Jaboticabal e Piracicaba como fontes de isolados promissores para uso em programas de Controle Biológico de pragas da ordem Lepidoptera. A coleção de Sete Lagoas, na qual as freqüências das subclasses estudadas foram relativamente baixas (abaixo de $20 \%$ ), destaca somente o gene cry $1 \mathrm{Ab}$, presente em $38,5 \%$ dos isolados desta coleção.
\end{abstract}

PALAVRAS-CHAVE: Variabilidade genética, gene cry, Bacillus thuringiensis.

\section{ABSTRACT}

BACILLUS THURINGIENSIS: GENETICDIVERSITY OF LEPIDOPTERA-SPECIFIC ISOLATES. The aim of this work was to genetically characterize 1,073 isolates of $B$. thuringiensis, from three Brazilian collections - UNESP/Jaboticabal, ESALQ/Piracicaba and EMBRAPA/Sete Lagoas - with the main emphasis on the analysis of the cry1 gene types presented by these isolates. To achieve this purpose, oligonucleotide primers were designed based on 16 conserved and 4 unconserved regions of the corresponding sequences from each one of the 16 subclasses of the cry 1 set of genes and used in PCR amplification assays. These sequences were amplified and the presence of amplicons for each subclass was evaluated in terms of percentage of gene type per bacterial collection. As a result, $55.7 \%$ of the isolates reacted to the primer Gral cry1, and the subclasses cry $1 A a, c r y 1 A b, c r y 1 A c, c r y 1 A d, c r y 1 A e, c r y 1 A f, c r y 1 A g, c r y 1 B f, c r y 1 C a$ and $c r y 1 F a$ were detected in high percentages among the isolates ranging from 43.4 to $54.9 \%$. A subclass distribution was observed among the set of isolates from these collections, with the greater percentage of isolates harboring the cry $1 \mathrm{Ab}(42.12 \%)$ and the lowest percentage for the cry $1 \mathrm{D} b$ subclass $(0.6 \%)$. The genetic variability of the analyzed bacterial collections seems to indicate the ESALQ/Piracicaba and the UNESP/Jaboticabal subsets as sources of promising isolates for the control of Lepidoptera pest insects. For the EMBRAPA/Sete Lagoas subset of isolates, in which the evaluated subclasses

\footnotetext{
${ }^{2}$ Universidade de São Paulo, Escola Superior de Agricultura "Luiz de Queiroz", Departamento de Entomologia, Fitopatologia e Zoologia Agrícola, Piracicaba, SP, Brasil.

${ }^{3}$ Universidade Federal do Espírito Santo, Centro de Ciências Agrárias, Departamento de Produção Vegetal, Alegre, ES, Brasil.

${ }^{4}$ EMBRAPA Milho e Sorgo, Sete Lagoas, MG, Brasil.
} 
frequencies were considered low (below 20\%), the cry $1 B$ was the most frequently observed gene type present in $38.5 \%$ of the isolates.

KEY WORDS: Genetic variability, cry gene, Bacillus thuringiensis.

\section{INTRODUÇÃO}

O controle de insetos-praga é um aspecto fundamental na produção agrícola, tanto para grandes como para pequenos produtores (MONNERAT; BRAVO, 1999). Nos últimos anos, tem sido alto o investimento na otimização de agentes de controle biológico mas, apesar disso, somente alguns bioinseticidas têm sido empregados. Estatísticas mostram que apenas 1\% das pragas agrícolas e vetores de doenças é controlado por compostos originários de organismos vivos. Entretanto, a bactéria Bacillus thuringiensis é responsável por 90-95\% desse mercado (VALADARES-InGLIS et al.,1998) e, em 1990, cobria uma área de 150.000 ha no Brasil (Alves, 1990).

Devido à sua grande importância ecológica, $B$. thuringiensis tem sido amplamente estudado, isolado de todos os ambientes onde foi procurado, apresentando grande variabilidade genética e uma ampla gama de sorotipos diferentes (VILAS-BôAS, 2002).

VILAS-BOAAS; LEMOS (2004) apresentaram a caracterização do conteúdo de genes cry como a principal motivação para a realização de amplos programas de busca de novas linhagens. A patogenicidade e a especificidade de uma linhagem são determinadas pelos tipos de genescry funcionais queoB. thuringiensis possui. Estes genes codificam para as proteínas Cry, que são sintetizadas na forma de protoxinas. Ao seremingeridas por uminseto suscetível, as protoxinas são solubilizadas no ambiente alcalino do intestino do inseto, e convertidas em $\delta$-endotoxinas. As toxinas hidrolisadas cruzam a membrana peritrófica, ligamse a receptores específicos nas células colunares do intestino médio, formando poros que aumentam a permeabilidade da membrana, interferindo no gradiente iônico e balanço osmótico da membrana apical. O aumento na absorção de água causa lise celular e eventual ruptura e desintegração das células do intestino médio. O inseto também pode morrer por inanição, uma vez que, pouco tempo após a infecção, ele para de se alimentar (Hofte;WHiteley, 1989; K NOWLES, 1994; Copping; MenN, 2000).

Até hoje, cerca de 300 genescry foram seqüenciados e classificados em 50 grupos e diferentes subgrupos dependendo da similaridade de seus aminoácidos. Mesmo considerando-se a variabilidade das proteínas Cry até agora descritas, é ainda extremamente necessária a busca por novas toxinas, visando o controle de um número maior de insetos. É também importante encontrar alternativas para o controle da resistência de insetos às toxinas $\mathrm{Cry}$, especialmente com o advento das plantas transgênicas (VILAS-BôAS; Lemos, 2004).

A busca e a caracterização de novos genes cry podem resultar em novas alternativas para o controle de espécies de insetos com nenhuma ou pouca susceptibilidade às proteínas $\mathrm{Cry}$ atualmente conhecidas, além de poder auxiliar no desenvolvimento de sistemas de manejo que evitem ou minimizem o aparecimento de resistência a $B$. thuringiensis em populações de insetos alvo em campo (VILAs-BÔAS, 2002). Atualmente, os casos mais graves de resistência ocorreram com a lagartaPlutella xylostella (TАВASHINIK etal., 1990; Ferré et al., 1991; TABASHINIK, 1994).

A caracterização de coleções de linhagens pode também auxiliar no entendimento do papel de $B$. thuringiensis no ambiente e da distribuição de genes cry. Assim, o trabalho de Feitelson et al. (1992) propôs que espécies de insetos e linhagens de $B$. thuringiensis vêm coevoluindo. Seguindo a mesma corrente de pensamento, Bravoet al. (1998) demonstraram que alguns genes cry foram distribuídos diferentemente em algumas regiões geográficas analisadas.

A variabilidade genética entre diferentes isolados de $B$. thuringiensis foi estudada principalmente através da utilização de técnicas que tem como base a PCR. Estas técnicas apresentam aplicações tais como a determinação da persistência da bactéria no ambiente (BOURQUE et al., 1993) e a predição da atividade tóxica de uma linhagem através da determinação do conteúdo de genes cry, muitas vezes evidenciando a presença de genes desconhecidos e, direcionando os trabalhos de bioensaio (SAUKA et al., 2006; IBARRA et al., 2003; BRAVOet al., 1998; CERÓN et al., 1994; 1995; С HAK et al., 1994; Kalman et al., 1993; CAROzZi et al., 1991).

Na busca por novos genes cry, várias coleções de linhagens de $B$. thuringiensis foram avaliadas (BERÓN; SALERMO, 2006; JaRA et al., 2006; KIM, 2000; Zhang et al., 2000; Bravo et al., 1998; Ben-Dov et al., 1997), mas poucas contemplaram amostras brasileiras (VILASBOAAs; LeMOS, 2004; IBARRA et al., 2003). Levando-se em consideração o fato de que o Brasil é um país que apresenta regiões com clima tropical e subtropical, contendo uma rica diversidade biológica, espera-se encontrar uma alta diversidade de isolados em solos brasileiros. Dentro deste contexto, o presente trabalho teve como objetivo caracterizar geneticamente 1.073 isolados de $B$. thuringiensis, com ênfase principal na análise dos tipos de genes cry 1 apresentados pelos isolados. 


\section{MATERIAL E MÉTODOS}

\section{Linhagens bacterianas}

Foram analisados 1.073 isolados de B.thuringiensis obtidos de vários pontos do território brasileiro, cedidos pelo Prof. Dr. Sérgio Batista Alves, do Laboratório dePatologia e Controle Microbiano de Insetos (Depto. deEntomologia, Fitopatologia e Zoologia Agrícola da ESALQ/USP), Piracicaba, SP, pelo Dr. Edílson Paiva (Núcleo de Biologia Aplicada da EMBRAPA Milho e Sorgo) Sete Lagoas, MG, e pelo Prof. Dr. Manoel Victor Franco Lemos (Depto. de Biologia Aplicada a Agropecuária), FCAV/UNESP, Jaboticabal. Todos os isolados encontram-seem estoques no Laboratório de Genética de Bactérias e Biotecnologia Aplicada na FCAV/UNESP - Jaboticabal.

\section{Extração de DNA}

Os isolados de B. thuringiensis foram previamente cultivados em placas contendo meio NA sólido, por $12 \mathrm{~h}$ a $30^{\circ} \mathrm{C}$. Para cada isolado uma colônia foi ressuspendida em $1 \mathrm{~mL}$ de água estéril em tubos de microcentrífuga e o material genético foi extraído utilizando-se o Kit InstaGene Matrix (Bio-Rad), conforme instruções do fabricante. As amostras de DNA obtidas foram estocadas em freezer $-20^{\circ} \mathrm{C}$ e mantidas até a utilização.

\section{Construção dos oligonucleotídeos iniciadores}

Os oligonucleotídeos iniciadores foram elaborados a partir das regiões conservadas das seqüências correspondentes à cada uma das 16 subclasses do gene cry 1 para a ordem Lepidoptera, obedecendo à lista de nomenclaturas das delta-endotoxinas de $B$. thuringiensis que são atualizadas constantemente e publicadas no site http:/ / www.lifesci.sussex.ac.uk/ home/Neil_Crickmore/Bt/toxins2.html. Para o alinhamento de todas as seqüências de cada subclasse utilizou-se o programa Clustal W (THOMPSON et al., 1994) e o programa Gene Runner 3.0 (Hastings Software, Inc.) para a elaboração dos iniciadores. Para algumas das subclasses cry 1 foram elaborados iniciadores também a partir de regiões não conservadas pela MWG (Ebersberg, Alemanha) e pela Bio Synthesis (Lewisville, EUA).

\section{Comprovação da presença de gene cry1 nos iso- lados}

Para a confirmação da presença de genescry1 nos isolados utilizou-se o par de iniciadores gerais, denominado Gral-cry1, segundo Bravo et al. (1998).

Após as amplificações, as eletroforeses foram realizadas segundo SAMBROOK; RUSSEL (2001).

\section{Identificação de subclasses do gene cry1}

A identificação das subclasses do gene cry1, nos isolados de $B$. thuringiensis estudados, foi realizada para 16 subclasses (Tabela 1). Para tanto, as reações de amplificação foram conduzidas, basicamente, nas mesmas condições realizadas para a verificação do gene $c r y 1$, anteriormente mencionado. Modificações ocorreram na temperatura de pareamento, para alguns iniciadores, conforme apresentados na Tabela 1.

Tabela 1 - Seqüências dos iniciadores para o gene cry1 e suas subclasses analisadas.

\begin{tabular}{|c|c|c|c|}
\hline Iniciador & Seqüências(5’-3’) & $\begin{array}{c}\text { Produto } \\
\text { Amplificado }(\mathrm{pb})\end{array}$ & $\begin{array}{c}\text { Temperatura } \\
\text { Pareamento }\left({ }^{\circ} \mathrm{C}\right)\end{array}$ \\
\hline cry1Aa conservada & $\begin{array}{l}\text { ATTTCCTTGTCGCTAACGC' } \\
\text { CCAAACACTGAAACATCTCTC' }\end{array}$ & 426 & 50 \\
\hline cry1Aa não conservada & $\begin{array}{l}\text { TTCGCATCATTTCTCCTTAG } \\
\text { CTGTCCACGATAAATGTTCC' }^{\prime}\end{array}$ & 1035 & 50 \\
\hline cry $1 A b$ conservada & $\begin{array}{l}\text { GAGATGTTTCAGTGTTTGGAC } \\
\text { GTCCCGTCAAGAACAGATAG }\end{array}$ & 799 & 50 \\
\hline$c r y 1 A b$ não conservada & $\begin{array}{l}\text { CGGGTAATCGCTCGTCTATC } \\
\text { CTTACTTCTCGCCCATTATCC }\end{array}$ & 640 & 50 \\
\hline cry1Ac conservada & $\begin{array}{l}\text { GGTGCTGGATTTGTGTTAGG } \\
\text { TTCTTTCTATGCCCTGAGCC }\end{array}$ & 712 & 50 \\
\hline cry1Ad conservada & $\begin{array}{l}\text { GAGATGTTTCAGTGTTTGGAC } \\
\text { GCTGGCACACTATTATCCTG }\end{array}$ & 750 & 50 \\
\hline
\end{tabular}

Continua... 
Tabela 1 - Continuação

\begin{tabular}{|c|c|c|c|}
\hline Iniciador & Seqüências(5'-3’') & $\begin{array}{c}\text { Produto } \\
\text { Amplificado }(\mathrm{pb})\end{array}$ & $\begin{array}{c}\text { Temperatura } \\
\text { Pareamento }\left({ }^{\circ} \mathrm{C}\right)\end{array}$ \\
\hline cry1Ae conservada & $\begin{array}{l}\text { GCTCTTACAACCGCTATTCC } \\
\text { TATTATCCTGTGGTGGTATTTC }\end{array}$ & 838 & 50 \\
\hline cry $1 A f$ conservada & $\begin{array}{l}\text { CСТTACAACCGCTATTCCTC } \\
\text { GTCCCGTCAAGAACAGATAG }\end{array}$ & 729 & 50 \\
\hline cry $1 A g$ conservada & $\begin{array}{l}\text { GAACAGTGCCCTTACAACCG } \\
\text { GTGGTTATTTGATGCCCTGAC }\end{array}$ & 558 & 50 \\
\hline$c r y 1 B b$ conservada & $\begin{array}{l}\text { CTTGTGTGTAGCCGAGGTG } \\
\text { TGCGTCTCTCAATAATAATAGG }\end{array}$ & 484 & 50 \\
\hline cry $1 B c$ conservada & $\begin{array}{l}\text { TATTGGGCGTATTAGGTGTG } \\
\text { TGCGTCTCTCAATAATAATAGG }\end{array}$ & 401 & 52 \\
\hline cry $1 B e$ conservada & $\begin{array}{l}\text { TAGGGATACGGCTCTTGCTC } \\
\text { CGATTCAAGTCTATGTCCCAC }\end{array}$ & 742 & 54 \\
\hline cry $1 B f$ conservada & $\begin{array}{l}\text { AACAAACGAGAGATTATTCCG } \\
\text { CGTTCTGTTGTTTCTGGTGG }\end{array}$ & 715 & 50 \\
\hline cry $1 \mathrm{Ca}$ conservada & $\begin{array}{l}\text { TGGTCAACTAACAAGGGAAG } \\
\text { TCTACTCCTTCAACACCACG }\end{array}$ & 393 & 50 \\
\hline cry1Ca não conservada & $\begin{array}{l}\text { AGAGCGGAGAAGAAGTGGAG } \\
\text { СТTCСТСTTCTACACAGTTGC }\end{array}$ & 559 & 50 \\
\hline cry1Da conservada & $\begin{array}{l}\text { GAAGGGAAGGAAATACAGAGC } \\
\text { GTTATTGGAGTGAAGAGTGTTG }\end{array}$ & 670 & 50 \\
\hline cry1Db conservada & $\begin{array}{l}\text { TTTATCCGTTTATGTTCAGGC } \\
\text { GATGCGGAAATAGTTACGGG }\end{array}$ & 600 & 50 \\
\hline cry1Ea conservada & $\begin{array}{l}\text { GAACTCAGCCATTAGAAGCC } \\
\text { ССТССTGTAAATCСTGGTCC }\end{array}$ & 609 & 48 \\
\hline cry1Fa não conservada & $\begin{array}{l}\text { AATGTAGAGCCGTTTGTTAGTG } \\
\text { CССTCAAGTTATTTAGACCTG }\end{array}$ & 595 & 50 \\
\hline
\end{tabular}

\section{RESULTADOS}

Dos 1.073 isolados de $B$. thuringiensis submetidos à análise, $11,4 \%$ eram da coleção da UNESPJaboticabal, 28,9\% da ESALQ-Piracicaba e 59,7 \% da EMBRAPA-Sete Lagoas, sendo as amostras coletadas de solo urbano, solos não cultivados e cultivados com cereais, hortícolas e frutíferas, silagem, insetos mortos, poeira acumulada em produtos estocados (cereais como milho, sorgo etc.), entre outros em diferentes estados do Brasil.

Os isolados das coleções foram previamente caracterizados em seus locais de origem como sendo $B$. thuringiensis, após minuciosa observação microscópica para a constatação da presença de inclusões cristalinas. Mesmo assim, uma amostragem realizada nas coleções da ESALQ - Piracicaba e EMBRAPA - Sete Lagoas foi submetida novamente à análise microscópica antes que elas integrassem o novo banco.

Na nova análise foi confirmada a presença de cristais protéicos, portanto, todas as 1.073 amostras foram devidamente etiquetadas e estocadas no LGBBA (UNESP-Jaboticabal).

Com a confirmação específica dos isolados de $B$. thuringiensis procedeu-se à extração de DNA total em quantidade e qualidade adequadas para as reações de amplificação. Essas amplificações para regiões de cada subclasse do gene cry 1 para alguns dos isolados da coleção podem ser observadas na Figura 1.

Na Figura 2 observa-se a distribuição das 16 subclasses do gene cry 1 , mais a família de genescry 1 , na coleção de isolados da UNESP - Jaboticabal. Notase que as porcentagens de isolados de $B$. thuringiensis para cada subclasse foi relativamente alta em sua maioria, nesta coleção. Assim, 55,7\% dos isolados 
reagiram com o par de iniciadores gerais Gral cry1, e as subclasse cry $1 A a, c r y 1 A b, c r y 1 A c$, cry $1 A d$, cry $1 A e$, cry $1 A f$, cry $1 A g$, e cry $1 B f$, cry1Ca e cry1Fa estão presentes em alta proporção de isolados, variando de $43,4 \%$ a $54,9 \%$.

Para as subclassescry $1 A a$, cry $1 A b$, cry 1 Caecry $1 F a$, foram observados os maiores números de isolados, quando utilizados os iniciadores provenientes de regiões não conservadas. Para as subclasses cry1Ca verificou-se diferença marcante quando utilizados iniciadores de regiões conservadas $(8,2 \%$ dos isolados) em relação aos iniciadores para regiões não conservadas (54,1\% dos isolados) (Fig. 2).

Provavelmente, os iniciadores elaborados a partir deregiões não conservadas poderiam amplificar maior número de diferentes genes desta subclasse, visto que, para a subclasse cry1 $1 A$, por exemplo, há várias subdivisões: cry1Aa1, cry1Aa2, cry1Aa3 etc. Menores porcentagens foram obtidas para as subclasses $c r y 1 B b$, cry $1 B c$, cry $1 B e, c r y 1 D a, c r y 1 D b$ e cry $1 E a$.

Verificou-se que a coleção da UNESP - Jaboticabal é muito rica em isolados portadores de genes para a subclasse cry $1 A$, sugerindo uma tendência de manutenção dessa proporção de isolados nas análises futuras com os demais genes desta subclasse. $\mathrm{O}$ fato de $55,7 \%$ dos isolados, na coleção, serem portadores do gene cry 1 indica sua a plicabilidade em programas de controle de pragas da ordem Lepidoptera.

Deve-se ressaltar que alguns isolados não apresentaram amplificação para a família cry1, com o par de iniciadores gerais Gral cry1, mas apresentaram para uma ou outra subclasse. Sugere-se, então, que estes iniciadores não são tão gerais e que nem todas as subclasses do gene cry1 foram contempladas e alinhadas por BRAvoet al. (1998), quando da elaboração desse par de iniciadores. O que se confirma pela crescente descoberta de novos genes cry1, agregados constantemente aos bancos de dados de seqüências.

Na coleção da ESALQ - Piracicaba (Fig. 3) nota-se que a distribuição das subclasses seguiu um perfil muito próximo ao da coleção de Jaboticabal, porém, com porcentagens menores de isolados dentro de cada subclasse.

Observou-se, nesta coleção, amplificação em 42,6\% dos isolados com os iniciadores gerais Gral cry1, mas dentre estes, 4,5; 4,2 e 3,2\% dos isolados não apresentaram amplificação para as subclassescry $1 A b$, cry $1 A e$ e cry $1 A g$, respectivamente (Fig. 3).

Houve baixa porcentagem de isolados (14,5\%) portadores da subclasse cry $1 A d$, quando comparada à coleção de Jaboticabal $(43,4 \%)$. No entanto, a subclasse $c r y 1 B$, continuou sendo a menos abundante seguida da subclasse cry1D.

Para a subclasse cry $1 C a$, o par de iniciadores para a região não conservada apresentou maior porcentagem de isolados $(41,9 \%)$, como na coleção da UNESP
- Jaboticabal (Fig. 2), contra 0,3\% para os iniciadores da região conservada.

Comparando-se a coleção da ESALQ - Piracicaba (Fig. 3) à coleção da UNESP-Jaboticabal (Fig. 2), maior porcentagem $(36,1 \%)$ de isolados apresentou a subclasse cry1Ea, enquanto a proporção de isolados contendo cry $1 \mathrm{Fa}$ foi menor $(33,9 \%)$.

A coleção da ESALQ-Piracicaba constitui-se também em excelente fonte de isolados efetivos no controle biológico de insetos da ordem Lepidoptera. No entanto, não se descarta a possibilidade de que os isolados das coleções referidas apresentem amplificação para as outras subclasses do gene cry1, ou para outras famílias específicas para outras ordens de insetos.

A coleção da EMBRAPA - Sete Lagoas apresentou um perfil de distribuição das subclasses estudadas totalmente diferente das outras duas coleções (Fig. 4). Apesar deser a coleção com maior número de isolados (641), foi a que apresentou a menor porcentagem de isolados portadores da subfamília cry $1 A$, considerada a mais comum entre os isolados de $B$. thuringiensis. Apenas 18,6\% dos isolados desta coleção apresentaram amplificação para o gene cry 1 com os iniciadores gerais, e somente para a subclasse $c r y 1 A b$, com iniciadores para região conservada, é que houve maior porcentagem de isolados $(38,5 \%)$.

A distribuição de isolados portadores da subclasse cry1B, no entanto, apresentou-se mais evidente que nas outras coleções (17 a 19\% dos isolados) (Fig. 4). Esta coleção apresenta um conjunto peculiar de isolados caracterizando um banco que deve ser intensamente explorado, visto que estes isolados de $B$. thuringiensis podem ser portadores de outras famílias de genes cry, bem como de outras subclasses com diferentes espectros de atuação contra insetos pragas, ou mesmo vetores de doenças.

Na Figura 5 pode ser observada a distribuição das 16 subclasses estudadas e da família cry1, considerando as três coleções conjuntamente, ou seja, a distribuição dentro dos 1073 isolados deB. thuringiensis. Essa distribuição foi mais homogênea entre as subclasses, com maior porcentagem de isolados portadores dos genes cry $1 A b(42,12 \%)$ e menor porcentagem de isolados que contém cry $1 D b(0,6 \%)$, verificando-se ainda que o banco de isolados de B. thuringiensis em estudo contempla todas as subclasses do gene cry1.

A caracterização específica destes isolados, por PCR, produziu diferentes perfis (combinações) de genes cry1. Devido ao tamanho da coleção, os isolados foram agrupados de acordo com o número de subclasses cry 1 exibido por cada um, conforme se observa na Figura 6, e pelas combinações mais freqüentes de genes cry 1 encontradas nos isolados (Tabela 2). 

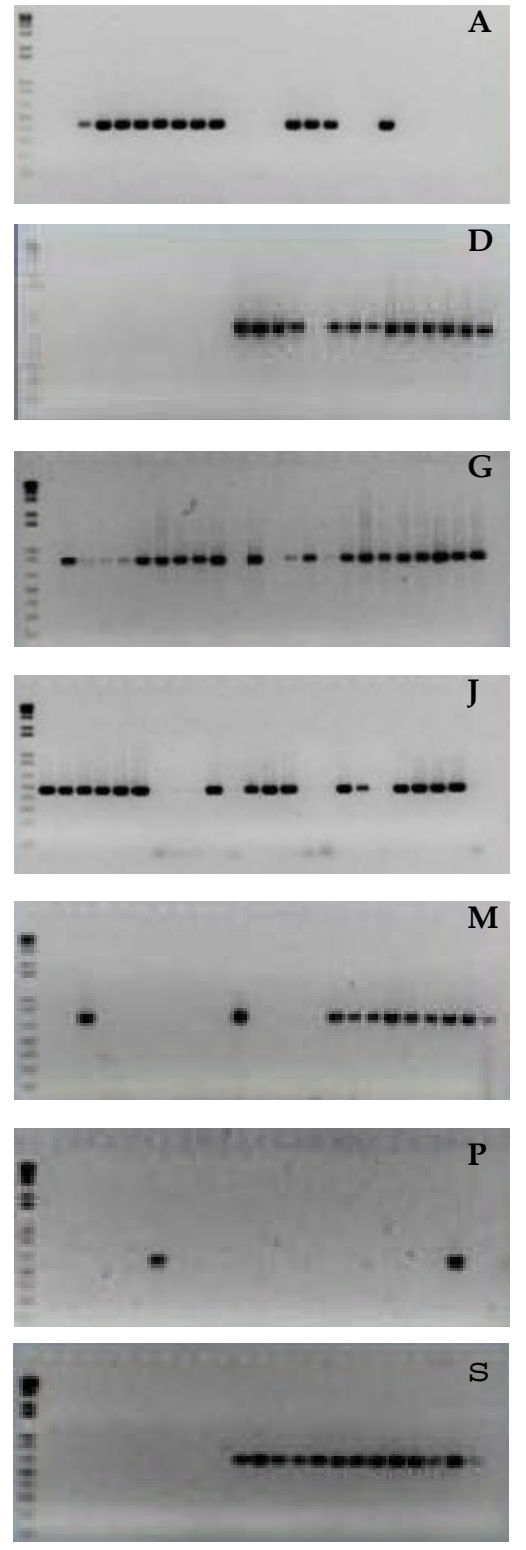

Fig. 1 - Eletroforeses evidenciando a amplificação para regiões de cada subclasse do gene cry1 para alguns dos isolados da coleção. A) cry1Aa conservada; B) cry1Aa não-conservada; C) cry1Ab conservada; D) cry1Ab não-conservada; E) cry $1 A c$ conservada; F) cry1Ad conservada; G) cry1Ae conservada; H) cry1Af conservada; I) cry1Ag conservada; J) cry1Bb conservada; K) cry1Bc conservada; L) cry1Be conservada; M) cry1Bf conservada; N) cry1Ca conservada; O) cry1Ca nãoconservada; P) cry1Db conservada; Q) cry1Ea conservada; R) cry1Fa conservada; S) cry1Da conservada.

Apesar da maioria dos isolados ter apresentado uma ou mais subclasses do gene cry $1,42,2 \%$ deles (453 isolados) não apresentaram amplificação para nenhuma delas. Cerca de $20 \%$ apresentaram uma das 16 subclasses analisadas, sendo a $c r y 1 A b$ a mais predominante.

Isolados que amplificaram de 9 a 13 genes constituem $22,2 \%$ dos isolados, sendo que a maioria apresenta os perfis de combinação de 10 e 11 subclasses. Ressalta-se aqui a presença de um isolado que apresentou amplificação para 14 subclasses, não amplifi- cando apenas para os genes cry1Ae, cry1Be e cry1E. Um número mais reduzido (10\%) apresentou perfis contendo de três a oito subclasses.

\section{DISCUSSÃO}

Poucos estudos têm relatado uma caracterização detalhada de coleções de $B$. thuringiensis em termos de conteúdo de genecry (Ben-Dov etal., 1996;BRavoetal.,1998; CHAK et al.,1994; FerRANDIS et al.,1999; URIBE et al., 2003). 
Tabela 2 - Combinações (perfis) mais freqüentes de genes cry1, e seus respectivos isolados, encontradas nesse estudo.

\begin{tabular}{|c|c|c|}
\hline Combinação de genes cry $1^{*}$ & Isolados & $\begin{array}{l}\mathrm{n}^{\mathrm{o}} \text { de } \\
\text { isolados }\end{array}$ \\
\hline $1,2,3,4,5,6,7,8,9,12,13,17$ & Br69, Br78, Br82, Br83, Br87, Br91 & 6 \\
\hline $1,2,3,4,5,6,7,8,12,13,16,17$ & $\begin{array}{l}\text { Br45, Br61, Br64, Br72, Br86, Br90, R203, R205, R206, R219, R220, R221, } \\
\text { R227, R230 }\end{array}$ & 14 \\
\hline $1,2,3,4,5,6,7,8,12,13,17$ & $\begin{array}{l}\text { Br8, Br9, Br10, Br11, Br12, Br16, Br17, Br58, Br70, Br71, Br84, Br93, 21.5A, } \\
\text { SP1, SP8, SP14, MT4, AM2 }\end{array}$ & 18 \\
\hline $1,2,3,4,5,6,7,8,12,17$ & MS9, MS10, PR5, PR6, PR11, MT1, MT3, RS1 & 8 \\
\hline $1,2,3,4,6,7,8,12,13,16,17$ & $\begin{array}{l}\text { Br46, Br48, Br60, Br74, R120, R122, R140, R146, R149, R157, R158, R161, } \\
\text { R162, R165, R166, R168, R177 R180, R181, R182, R184, R193, R199, R223, } \\
\text { R224, R228 }\end{array}$ & 26 \\
\hline $1,2,3,4,6,7,8,12,13,16$ & R25, R26, R27, R33, R54, R70, R73, R75, R77, R81, R83, R84, R144 & 13 \\
\hline $1,2,3,4,6,7,8,13,16,17$ & R232, R233, R235, R240, R248, R249, R254, R258, R259 & 9 \\
\hline $1,2,3,4,6,8,12,13,16,17$ & R144, R148, R155, R156, MS4 & 5 \\
\hline $1,2,3,6,7,8,12,13,16,17$ & R121, R123, R125, R139, R164, R169 & 6 \\
\hline $1,2,3,9,10,11,12,13,14,16,17$ & $\begin{array}{l}1139 \mathrm{H}, 1140 \mathrm{~B}, 1140 \mathrm{C}, 1150 \mathrm{C}, 939 \mathrm{FB}, 939 \mathrm{FC}, 1119 \mathrm{~A}, 1119 \mathrm{C}, 1134 \mathrm{~B}, 1134 \mathrm{C}, \\
1136 \mathrm{C}, 1136 \mathrm{~B}, 1136 \mathrm{~B}, 1138 \mathrm{~A} 1119 \mathrm{C}, 1139 \mathrm{D}, 1036 \mathrm{C}, 1124 \mathrm{E}, 1128,1129 \mathrm{~A}, \\
1130 \mathrm{D}, 1132 \mathrm{~A}, 1130 \mathrm{C}\end{array}$ & 23 \\
\hline $1,2,9,10,11,12,13,14$ & E28, E39, 41.7L, 42.7L, 43.7L, 44.7L, 45.7L, 47.7L & 8 \\
\hline 1,3 & $\begin{array}{l}\text { 858B2, 933D3, 939E, 939G, 939N, 939S, 940B, 940I, 961B, 965A, 972A, } \\
\text { 1010D, 1043N-N }\end{array}$ & 13 \\
\hline $1,9,10,11,12,13,14,15$ & E42, E43, E44, E45, E46, E47, E48, E49, E50 & 9 \\
\hline 1 & 937BF, 944B, 1008B, 1009A, 1043I & 5 \\
\hline 3,16 & $\begin{array}{l}\text { R208, R209, R210, R213, R215, 842C, 862CF1, 889GG, 890BA, 890BB, 941L, } \\
\text { 946H, 946JR, 946L, 957A, 964A, 964C, 965C, 969B, 977F, 999, CST23 }\end{array}$ & 22 \\
\hline 3 & $\begin{array}{l}\text { 884A3B, 1120D, R170, R265, 702, 846J, 851C, 857 AC2, 857B, 858AB4, 858AB5, } \\
\text { 858B1, 868C1, 868C2, 868C3, 868C5,868C8, 884A1.C, 884A3.D, 884A3.E, } \\
\text { 884A3.G, 887AA, 927A2, 927A3, 927A4, 927A6, 927A7, 927A7.10, 927A9, } \\
\text { 927A9.1, 927A9.5, 927A9.7, 927A9.8, 927A9.12, 927A9.13, 927A9.17, 927A9.19, } \\
\text { 927C, 927F, 927G, 927N, 927K, 933A, 933D2, 933D2A, 933D2B, 933D2D, } \\
\text { 933D2E, 933D2F, 933D2G, 933D2H, 933F, 933L, 937C, 937K, 938A, 938E, 939, } \\
\text { 939A, 939B, 939C, 939D, 939D3, 940C, 940CI, 940H, 940J, 941CC, 941CD, } \\
\text { 941CG, 941CO, 941CF, 941I, 941K, 941M, 943B, 945D, 945E, 946B, 946F, 946JO, } \\
\text { 947A, 948, 948F, 951AG, 951B, 952B, 952C, 955A, 957BB, 957BJ, 957BB, 957BJ, } \\
\text { 957BK, 963, 964B, 964D, 965, 965E, 972C, 972CA, 974C, 976B, 976C, 977D, 981, } \\
\text { 986H, 986L, 986N, 987B, 993, 1001A, 1007, 1059A, 1060C, 1060D, 1061C, } \\
\text { 1063D, 1066B, 1067B, 1067D, 1067I, 1068E, 1068F, 1071, 1072, 1123D, 1148D }\end{array}$ & 128 \\
\hline 6 & E27, S497, R49, R98, R113, R114, R116, 118, R126, R128, R129, MBT & 12 \\
\hline 9 & S251, S284, S350, S1349, R2, R35, R52, 69.24A, S385, 854, 1133A & 11 \\
\hline 10 & S98, R12, R62, R64, R66, R71, R72, R90, 1033I, 1034D, 970F, 977B & 12 \\
\hline 12 & 970, S75, 815C, 816, 856A, 868A, 878A, 1062C & 8 \\
\hline 16 & $\begin{array}{l}\text { R160, R171, R196, R197, R198, R201, R225, R274, 933C, 933K, 937F, 937I, } \\
\text { 948C, 960, 965M, 971H, 978 1073B, CST Seiva, Seiva, 106.12A, E13, 6.7L }\end{array}$ & 23 \\
\hline
\end{tabular}


CHAK et al. (1994), trabalhando com amostras de solos provenientes de Taiwan, obtiveram 225 isolados dos quais $221(98,2 \%)$ continham genes cry 1 . Destes, somente cinco diferentes perfis de genes cry foram encontrados usando iniciadores específicos para cry1, cry3, ecry4. Nenhum dos isolados apresentou genes cry3. BEN-Dov et al. (1996), quando analisaram 215 isolados obtidos de amostras de Israel, pelo uso de iniciadores gerais e específicos para genes cry1, cry2, cry3, cry4, cry7, e cry8, encontraram genes cry 1 representados por 16 diferentes perfis. BRAVOetal. (1998) relataram que, de um total de 496 isolados obtidos de diferentes ecossistemas no México, 246 isolados $(49,6 \%)$ continham genescry 1 apresentando 35 diferentes perfis usando iniciadores específicos para genes cry1, cry3, e cry7. Também FERRANDIs et al. (1999), na Espanha, verificaram que, de 223 isolados de $B$. thuringiensis, 121 (54,3\%) continham gene cry1, e encontraram ainda 16 diferentes perfis nesses isolados após terem realizado análises com os iniciadores para os genes cry 1, cry 2 e cry 4 .

O presente estudo relata 16 diferentes subclasses do gene cry 1 em 621 dos 1.073 isolados em estudo, provenientes de diferentes ecossistemas no Brasil, usando iniciadores específicos para os genes cry1. A grande variabilidade e distribuição de B. thuringiensis nos estudos em diversos países sugerem que as diferenças ecológicas do local de origem e/ ou as relações de co-evolução tenham favorecido a expressão de diferentes padrões de genes cry1.

Chaket al. (1994) eBravoet al. (1998) encontraram padrão similar e, em ambos os trabalhos, o perfil mais comum de gene cry 1 correspondeu aos genes $c r y 1 A a, c r y 1 A b$ e cry $1 A c$, o que pôde ser observado, também no presente estudo, nas coleções de Jaboticabal e Piracicaba, que apresentaram comportamento semelhante quanto à distribuição dos perfis de genescry1. Ainda, CHAKet al. (1994) encontraram importante freqüência entre os perfiscry $1 \mathrm{Aa} / \mathrm{cry} 1 \mathrm{Ac}$ e cry $1 C / c r y 1 D$ em 21,3 e $17,7 \%$ dos isolados, respectivamente. No mesmo contexto, FERRANDIs et al.(1999) mostraram que $93 \%$ dos isolados com presença do gene cry $1 C$ continham o gene cry $1 D$ no seu genoma, sugerindo então, alta ligação genética entre esses dois genes.

Segundo SANCHIS et al. (1988), a linhagem padrão de $B$. thuringiensis subsp. Aizawai 7.29 contém genes cry1C e cry1D no mesmo replicon. As análises aqui apresentadas corroboram com esses autores, visto que nas três coleções, muitos isolados que apresentaram o gene $c r y 1 C$ também continham o gene cry $1 D$ (Tabela 2). Todos esses resultados indicam que os pares de genes mencionados encontram-se juntos na natureza, provavelmente fazendo parte do mesmo replicon, localizados em um megaplasmídeo (GONZÁLES et al., 1982; SANCHIS et al., 1988).
A ocorrência conjunta de alguns desses cry pode minimizar problemas relacionados a inseticidas baseados em $B$. thuringiensis, devidoao seu espectrodeação limitadoquandocomparadoaos inseticidas químicos. Esteéumfator limitantejáqueasculturas agrícolas são atacadas simultaneamente por diferentes pragas e, às vezes, por insetos de diferentes ordens. Portanto, uma importante característica encontrada neste estudo é a presença de mais que um gene cry 1 na maioria dos isolados (Fig. 6). De 621 isolados, 399 apresentaram duas ou mais subclasses do gene cry1. No entanto, deve-se ressaltar que, para alguns genes cry1, os iniciadores elaborados podem ter amplificado mais de uma subclasse, por estarem em uma região de homologia entre elas, levando a um número superestimado de genesemalgunsisolados; comoexemplo, oisoladoque apresentou 14 subclasses (Fig. 6). Isso só poderia ser verificado através do seqüenciamento dos produtos amplificados ecomparação com as seqüências depositadas no banco de dados.

Há alguns genes cry que são comumente identificados em todas as coleções do mundo, tais como os genes cry1; e outros são mais freqüentes em uma região que em outra. Por exemplo, os genes cry $1 A$, cry1C, cry1D e genes cry2 foram mais comumente encontrados em isolados da Ásia (BEN-Dov et al.,1997; KIM, 2000; Zhang et al., 2000) que naqueles da América Latina (BRAvoetal., 1998). O mesmo não ocorreu neste trabalho, onde cry $1 A$ e cry $1 C$ apresentaram alta freqüência.

A variabilidade gênica nas coleções analisadas destaca as coleções de Jaboticabal e Piracicaba, como fonte deisolados promissores para uso em programas deControle Biológico de pragas da ordem Lepidoptera, diferentemente do observado para a coleção da EMBRAPA - Sete Lagoas, na qual as freqüências das subclasses estudadas foram relativamente baixas (abaixo de 20\%), com destaque somente para o gene cry $1 A b$, presente em $38,5 \%$ dos isolados desta coleção.

Desde que resistência a $B$. thuringiensis em populações de insetos da ordem Lepidoptera tem sido relatada (FERRÉ et al., 1991; TABASHNIK, 1994), há um grande interessenoisolamentodenovaslinhagens deB. thuringiensis cujas propriedades tóxicas diferem daquelas já usadas como bioinseticidas. Os resultados obtidos aqui mostram que o Brasil apresenta-se como uma fonte potencialmente rica em isolados de $B$. thuringiensis, mas a possibilidade em usar essas toxinas a partir de novos isolados requer ainda estudos mais detalhados.

\section{AGRADECIMENTOS}

À FAPESP pelo apoio financeiro. Ao Dr. Edílson Paiva (CNPMS/EMBRAPA) pelo envio dos isolados da coleção de Sete Lagoas. 


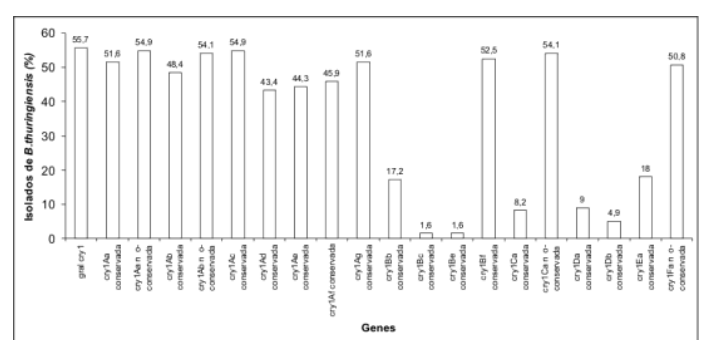

Fig. 2 - Distribuição das subclasses do gene cry1 nos isolados da Coleção da UNESP - Jaboticabal.

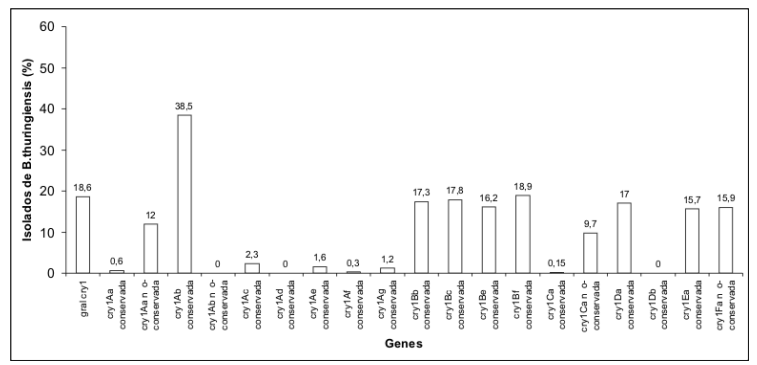

Fig. 4 - Distribuição das subclasses do gene cry1 nos isolados da EMBRAPA - Coleção de Sete Lagoas.

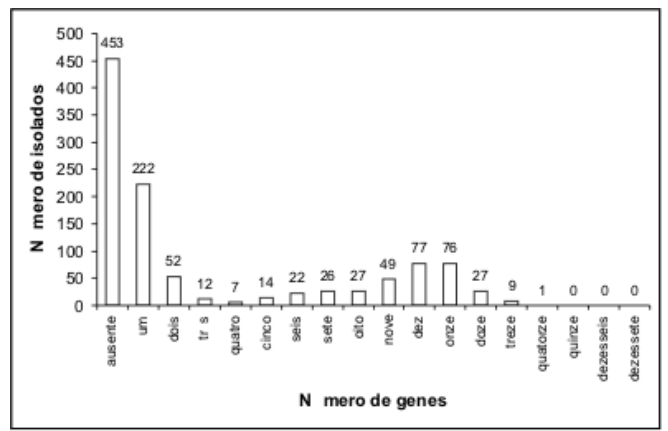

\section{REFERENCIAS}

ALVES, S.B. Controle Microbiano de Insetos. In: Crocomo, W.B. Manejo integrado de pragas, São Paulo, Editora Unesp, 1990, p.147-176.

BEN-DOV, E.; EIVAN, M.; PERLEG, N.; BOUSSIBA, S.; ZARISTSKY, A. Restriction map of the 125-kilobase plasmid of Bacillus thuringiensis subsp israelensis carryng the genes that encode delta-endotoxins active against mosquito larvae. Applied and Environmental Microbiology, Washington, v.62, n.9, p.3140-3145, 1996.

BEN-DOV, E.; ZARISTSKY, A.; DAHAN, E.; BARAK, Z.; SINAI, R.; MANASHEROB, R.; KHAMRAEV, A.; TROITSKAYA, E.; DUBITSKY, A.; BEREZINA, N.; MARGALITH, Y. Extended screening by PCR for seven cry-group genes from field-collected strains of Bacillus thuringiensis. Applied and Environmental Microbiology, Washington, v.63, n.12, p.4883-4890, 1997.

BERÓN C.M.; SALERNO, G.L. Characterization of Bacillus thuringiensis isolates from Argentina that are potentially useful in insect pest control. BioControl, Netherlands, v.51, n.06, p.779-794, 2006.

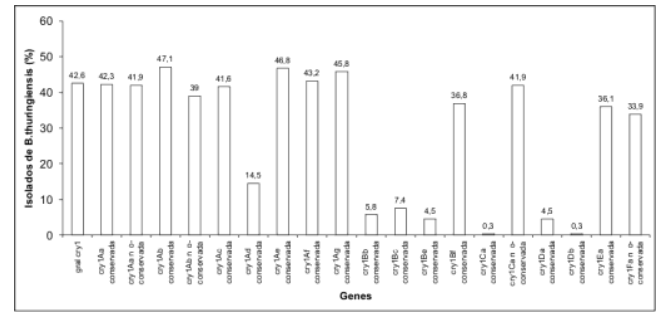

Fig. 3 - Distribuição das subclasses do gene cry1 nos isolados da Coleção da ESALQ - Piracicaba.

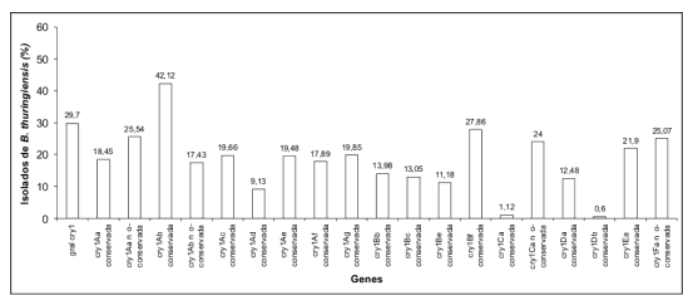

Fig. 5 - Distribuição das 16 subclasses do gene cry1 (iniciadores específicos) e cry1 (iniciadores gerais) presentes na coleção de isolados de $B$. thuringiensis em estudo.

Fig. 6 - Número de subclasses do gene cry1 presentes nos isolados da coleção em estudo.
BOUROUE, S.N.; VALERO, J.R.; MERCIER, J; LAVOIE, M; LEVESQUE, R. C. Multiplex polymerase chain reaction for detection and differentiation of the microbial insecticide Bacillus thuringiensis. Applied and Environmental Microbiology, Washington, v.59, n.2, p.523-527, 1993.

BRAVO, A.; SARABIA, S.; LOPEZ, L.; ABARCA C.; ORTIZ, A.; ORTIZ, M.; LINA, L.; VILLALOBOS, F.J.; PEÑA, G.; NUÑEZ-VALDEZ, M.E.; SOBERÓN, M; QUINTERO, R. Characterization of cry genes in a mexican Bacillus thuringiensis strain collection. Applied and Environmental Microbiology, Washington, v.64, n.12 p.4965-4972, 1998.

CAROZZI, N.B.; KRAMER, V.C.; WARREN, G.W.; EVOLA, S.; KOZIEL, M.G. Prediction of insectidal activity of Bacillus thuringiensis strains by polymerase chain reaction product profiles. Applied and Environmental Microbiology, Washington, v.57, n.11, p.3057-3061, 1991.

CERÓN, J; ORTIZ A.; QUINTERO, R., GÜERECA, L.; BRAVO, A. Specific PCR primers directed to identify cryI and cryIII genes within Bacillus thuringiensis strain 
collection. Applied and Environmental Microbiology, Washington, v.61, n.11, p.3826-3831, 1995.

CERÓN,J; COVARRUBIAS, L.; QUINTERO, R.; ORTIZ, A.; ORTIZ, M.; ARANDA, E.; LINA, L.; BRAVO A. PCR analysis of the cryI insecticidal crystal family genes from Bacillus thuringiensis. Applied and Environmental Microbiology, Washington, v.60, n.01, p.353-356, 1994.

CHAK, K.F., CHAO, D.C., TSENG, M.Y., KAO, S.S., TUAN, S.J., FENG, T.Y. Determination and distribution of cry-type genes of Bacillus thuringiensis isolates from Taiwan. Applied and Environmental Microbiology, Washington, v.60, n.7, p.2415-2420, 1994.

COPPING, L.G.; MENN, J.J. Review biopesticides: a review of their action, applications and efficacy. Pest management science, Sussex, v.56, n.88, p.651-676, 2000.

FEITELSON, J.S.; PAYNE, J.; KIM, L. Bacillus

thuringiensis: insects and beyond. Nature Biotechnology, New York, v.10, p.271-275, 1992.

FERRANDIS, M.D.; JUÁREZ-PÉREZ, V.M.; FRUTOS, R.; BEL, Y.; FERRÉ, J. Distribuition of cryI, cryII and cry $\mathrm{V}$ genes within Bacillus thuringiensis isolates from Spain. Systematic and Applied Microbiology, Jena, v.22, n.2, p.179-185, 1999.

FERRÉ, J.; REAL, M.D.; VAN RIE, J.; JANSENS, S.; PEFEROEN, M. Resistance to the Bacillus thuringiensis bioinsecticide in a field population of Plutella xylostella is due to a change in a midgut membrane receptor. Proceedings of the National Academy of Sciences of the United States of America, Washington, v.88, n.12, p.5119-5123, 1991.

GONZALEZ, J.M JR; BROWN, B.J; CARLTON, B.C. Transfer of Bacillus thuringiensis plasmids coding for delta-endotoxin among strains of $B$. thuringiensis and B. cereus. Proceedings of the National Academy of Sciences of the United States of America, Washington, v.79, n.22, p.6951-6955, 1982.

HOFTE, H.; WHITELEY, H.R. Insecticidal crystal proteins of Bacillus thuringiensis. Microbiological Reviews, Washington, v.53, n.2, p.242-255, 1989.

IBARRA, J.E.; DEL RINCON, M.C.; ORDUZ, S.; NORIEGA, D.; BENINTENDE, G.;. MONNERAT, R.; REGIS, L.; OLIVEIRA, C.M.; LANZ, H.; RODRIGUEZ, M.H.; SANCHEZ, J.; PENA, G.; BRAVO, A. Diversity of Bacillus thuringiensis strains from Latin America with insecticidal activity against different mosquito species. Applied and Environmental Microbiology, Washington, v. 69, n.09, p.5269-5274, 2003.

JARA, S.; MADUELL, P.; ORDUZ, S. Diversity of Bacillus thuringiensis strains in the maize and bean phylloplane and their respective soils in Colombia. Journal of Applied Microbiology, Oxon, v.101, n.01, p.117-124, 2006.

KALMAN, S.; KIEHME, K.L.; LIEBS, J.L; YAMAMOTO, T. Cloning of a novel cryIC-type gene from a strain of Bacillus thuringiensis subsp. galleriae. Applied and Environmental Microbiology, Washington, v.59, n.04, p.1131-1137, 1993.

KIM, H.S. Comparative study of the frequency, flagellar serotype, crystal shape, toxicity, and cry gene contents of Bacillus thuringiensis from three environments. Current Microbiology, New York, v.41, n.04, p.250-256, 2000.
KNOWLES, B.H. Mechanism of action of Bacillus thuringiensis insecticidal $\delta$-endotoxins. Advances in Insect Physiology, London, v.24, p.275-308, 1994.

MONNERAT, R.; BRAVO, A. Proteínas bioinseticidas produzidas pela bactéria Bacillus thuringiensis: modo de ação e resistência. In: Mello, I.S., Azevedo, J.L. Controle Biológico, Jaguariúna, 1999, v.3, p.163-200.

SAMBROOK, J.; RUSSEL, DW. Molecular cloning: a laboratory manual. New York: Cold Spring Harbor Laboratory Press, Cold Spring Harbor, 2001.

SANCHIS, V.; LERECLUS, D.; MENOU, G.; CHAUFAUX, J.; LECADET, M.M. Multiplicity of $\delta$ endotoxin genes with different specificities in Bacillus thuringiensis aizawai 7.29. Molecular Microbiology, Oxon, v.2, n.03, p.393-404, 1988.

SAUKA, D.H.; COZZI, J.G.; BENINTENDE, G.B. Detection and identification of cry1I genes in Bacillus thuringiensis using polymerase chain reaction and restriction fragment length polymorphism analysis. Current Microbiology, New York, v.52, n.1, p.60-63, 2006.

TABASHNIK, B.E. Evolution of resistance to Bacillus thuringiensis. Annual review of entomology, Palo Alto, v.39, n.47-79, 1994.

TABASHNIK, BE.; CUSHING, NL; FINSON, N.; JOHNSON, MW. Field development of resistance to Bacillus thuringiensis in diamondback moth (Lepidoptera: Plutellidae). Journal of Economic Entomology, Lanham, v.83, n.05, p.1671-1676, 1990.

THOMPSON, J.D.; HIGGINS, D.G.; GIBSON, T.J.; CLUSTAL, W. Improving the sensitivity of progressive multiple sequence alignment through sequence weighting, position-specific gap penalties and weight matrix choice. Nucleic Acids Research, England, v.22, n.22, p.4673-4680, 1994

URIBE, D.; MARTINEZ, W.; CERÓN, J. Distribution and diversity of cry genes in native strains of Bacillus thuringiensis obtained from different ecosystems from Colombia. Journal of Invertebrate Pathology, San Diego, v.82, n.02, p.119-127, 2003.

VALADARES-INGLIS, M.C.C.; SHILER, W.; DESOUZA, M.T. Engenharia genética de microrganismos agentes de controle biológico. In: Mello, I.S., Azevedo, J.L. Controle Biológico, Jaguariúna, 1998, v.01, p.201-230.

VILAS-BÔAS, G.F.L.T. Diversidade e estrutura genética de populações de Bacillus thuringiensis e de Bacillus cereus. 2002. 103p. Tese (Doutorado - Microbiologia Agropecuária) - Faculdade de Ciências Agrárias e Veterinárias UNESP, Jaboticabal, 2002.

VILAS-BÔAS, G.T.; LEMOS, M.V. Diversity of cry genes and genetic characterization of Bacillus thuringiensis isolated from Brazil. Canadian Journal of Microbiology, Ontario, v.50, n.8, p.605-613, 2004.

ZHANG, H.Y.; YU, Z.N.; DENG, W.X. Composition and ecological distribution of Cry proteins and their genotypes of Bacillus thuringiensis isolates from warehouses in China. Journal of Invertebrate Pathology, San Diego, v.76, n.03, p.191-197, 2000.

Recebido em 23/2/07

Aceito em $02 / 10 / 08$ 